\title{
Discrepancy of p16 immunohistochemical expression and HPV RNA in penile cancer. A multiplex in situ hybridization/ immunohistochemistry approach study
}

Federica Zito Marino', Rosalaura Sabetta ${ }^{1}$, Francesca Pagliuca', Matteo Brunelli², Gabriella Aquino ${ }^{3}$, Sisto Perdonà ${ }^{4}$, Gerardo Botti ${ }^{3}$, Gaetano Facchini ${ }^{5}$, Francesco Fiorentino ${ }^{6}$, Giovanni Di Lauro ${ }^{7}$, Marco De Sio ${ }^{8}$, Ferdinando De Vita ${ }^{9}$, Giorgio Toni ${ }^{10}$, Rodolfo Borges Dos Reis ${ }^{11}$, Luciano Neder ${ }^{12,13}$ and Renato Franco ${ }^{1 *}$

\begin{abstract}
Background: The high-risk human papillomavirus (HPV) infection represents one of the main etiologic pathways of penile carcinogenesis in approximately $30-50 \%$ of cases. Several techniques for the detection of HPV are currently available including Polymerase chain reaction-based techniques, DNA and RNA in situ hybridization (ISH), p16 immunohistochemistry $(\mathrm{IHC})$. The multiplex HPV RNA ISH/p16 IHC is a novel technique for the simultaneous detection of HPV E6/E7 transcripts and p16INK4a overexpression on the same slide in a single assay. The main aim of this study was to evaluate the discrepancy of p16 IHC expression relatively to HPV RNA ISH in penile cancer tissue.
\end{abstract}

Methods: We collected a series of 60 PCs. HPV has been analysed through the RNA ISH, p16 IHC and the multiplex HPV RNA ISH/P16 IHC.

Results: The multiplex HPV RNA ISH /p16 IHC results in the series were in complete agreement with the previous results obtained through the classic p16 IHC and HPV RNA scope carried out on two different slides. The multiplex HPV RNA ISH /p16 IHC showed that HPV positivity in our series is more frequently in usual squamous cell carcinoma than in special histotypes (19 out of $60-15 \%$ - versus 6 out of $60-10 \%$-), in high-grade than in moderate/low grade carcinomas ( 6 out of $60-10 \%$ - versus 4 out of $60-6.7 \%$-). In addition, our data revealed that in 5 out of 20 cases with p16 high intensity expression is not associated with HPV RNA ISH positivity.

Conclusions: Our findings emphasize that the use of p16 as a surrogate of HPV positivity was unsuccessful in approximatively $8 \%$ of cases analysed in our series. Indeed, p16 IHC showed a sensitivity of $100 \%$ and a specificity of $71 \%$, with a positive predictive value (PPV) of $54 \%$ and a negative predictive value of $100 \%$; when considering high intensity, p16 IHC showed a sensitivity of $100 \%$, a specificity of $89 \%$, with a PPV of $75 \%$ and NPV of $100 \%$. Since HPV positivity could represent a relevant prognostic and predictive value, the correct characterization offered by this approach appears to be of paramount importance.

Keywords: ISH, HPV, p16, Penile carcinoma, Multiplex HPV RNA ISH /p16 IHC

\footnotetext{
* Correspondence: renato.franco@unicampania.it

${ }^{1}$ Pathology Unit, Department of Mental and Physical Health and Preventive Medicine, University of Campania "L. Vanvitelli", Complesso di Santa Patrizia, Via Luciano Armanni, 5, 80138 Naples, Italy

Full list of author information is available at the end of the article
}

C C The Author(s). 2021 Open Access This article is licensed under a Creative Commons Attribution 4.0 International License, which permits use, sharing, adaptation, distribution and reproduction in any medium or format, as long as you give appropriate credit to the original author(s) and the source, provide a link to the Creative Commons licence, and indicate if changes were made. The images or other third party material in this article are included in the article's Creative Commons licence, unless indicated otherwise in a credit line to the material. If material is not included in the article's Creative Commons licence and your intended use is not permitted by statutory regulation or exceeds the permitted use, you will need to obtain permission directly from the copyright holder. To view a copy of this licence, visit http://creativecommons.org/licenses/by/4.0/ The Creative Commons Public Domain Dedication waiver (http://creativecommons.org/publicdomain/zero/1.0/) applies to the data made available in this article, unless otherwise stated in a credit line to the data. 


\section{Background}

Penile carcinoma (PC) is a rare and aggressive disease with an incidence of $0.4 \%$ in the United States and Western Europe, while the incidence is higher in less developed countries, including Africa, Asia and South America, estimated around $6.0 \%$ [1-3]. The most frequent histotype is the conventional squamous cell carcinoma with or without keratinization, accounting for approximatively $70-75 \%$ of cases, followed by basaloid, sarcomatoid and warty subtypes. The verrucous and condylomatous subtypes are rare histotype with a much better prognosis [4].

The PC development can be attributed to two different pathogenic pathways, the chronic inflammation of the lichen sclerosus being the most frequent ; then the infection by the high-risk human papilloma virus (HPV) is relatively less common [2, 4-6]. Indeed, the frequency of $\mathrm{HPV}$ related $\mathrm{PC}$ ranges from 30 to $50 \%$. Genotypes more frequently detected are $16,18,31,33,45,56$, and 65 [4, 7-10]. HPV-related PC constitutes a specific subset with a good prognosis, since the 5year diseasespecific survival of such patients is better than patients with HPVurelated PC (93\% vs. $78 \%)[11,12]$.

The new World Health Organization (WHO) attributes a great importance to HPV-related cancer, revising the previous classification of PCs based exclusively on the morphology. Thus, PCs are subtyped the into HPVrelated and HPV-unrelated tumors [13, 14].

The main HPV-related subtypes are frequently basaloid and warty carcinomas, while the conventional squamous cell carcinoma, the papillary and the verrucous carcinomas are mainly non-HPV-related [4, 13, 15].

The HPV can be detected through direct and indirect different assays, including the polymerase chain reaction (PCR), p16 immunohistochemistry (IHC) and in situ hybridization (ISH) analysis. PCR assay detects HPV DNA identifying both transient and persistent infections. This method is a highly sensitive and it allows the identification of the different genotypes of the virus $[16,17]$. ISH analysis allows HPV detection preserving the morphological context, allowing the HPV locations in the tumor tissue. Several studies reported high sensitivity and specificity of DNA ISH in PC, whereas RNA ISH is not frequently used to detect HPV in such cancer [18-20].

IHC represents a surrogate method to detect HPV infectious, since it is based on the identification of the p16 expression, being considered as a marker for high-risk $\mathrm{HPV}$-induced transformation. Indeed, since p16 is accumulated as an effect of HPV E7 oncoprotein, its overexpression seems to be a critical early event in carcinogenesis [21]. Thus, it is commonly used in the clinical practice, also in the diagnosis of HPV-related cancers in other anatomic sites. Although p16 IHC expression has been established as a highly valid surrogate marker, previous data showed a disagreement between HPV infectious detected through molecular approach and p16 IHC expression [22-24]. Indeed, as previously reported in other HPV-related cancer types, such as cervical cancers and oropharyngeal squamous cell carcinoma (OPSCC), RNA ISH could be a useful tool to identify HPV infectious in all cases where p16 IHC or DNA ISH test are negative or equivocal for [25, 26]. We previously developed a new multiplex approach to identify HPV infectious carrying out HPV RNA ISH and p16 IHC on the same slide to simultaneously detect HPV E6/E7 transcripts and p16INK4a overexpression [25]. We validated this novel assay in a histopathological series including cervical cancers and OPSCCs [25]. This multiplex approach could improve the detection of HPV in PCs, contributing to a better classification of HPVrelated PCs. In this view, we have analysed the HPV in a multicentric series of PCs using the multiplex HPV RNA ISH /p16 IHC assay.

\section{Methods \\ Specimens}

A series of 60 penile carcinomas were included in our study. All cases were collected in our records at the University of Campania "L. Vanvitelli" Hospital, the Istituto Nazionale Tumori, Fondazione G. Pascale, the S.M. delle Grazie Hospital and the University Ribeirão Preto Hospital of São Paulo,. The series included surgical samples and wide biopsies, formalin-fixed paraffin-embedded (FFPE) samples. Sections of $4 \mu \mathrm{m}$ thickness from each block with a mean of 3 blocks per tumor) were stained with hematoxylin-eosin. All cases were reviewed according to the WHO histopathological classification $[13,14]$.

\section{p16 immunohistochemistry}

p16 IHC was carried out with a proprietary kit CIN tec Histology; MTM laboratories AG) using the clone E6H4 on a Ventana Benchmark autostainer (Ventana Medical Systems, Tucson, AZ, USA) for the detection of p16INK4a antigen. A cervical carcinoma with high p16 expression was used as a positive control. The primary antibody was omitted from negative controls.

In our analysis we identified the subgroups with different p16 IHC staining, as follows: p16 high expression: tumors with staining $\geq 70 \%$ nuclear and cytoplasmic staining; p16 moderate expression: tumors with staining 30-70\% nuclear and cytoplasmic staining; p16 low expression: tumors with staining $10-30 \%$ nuclear and cytoplasmic staining; p16 negative: tumors with staining 1-10\% nuclear and cytoplasmic staining. In addition, also intensity was evaluated as previously reported [24]. The slides were independently evaluated by three separate observers. 


\section{Automated HPV RNA in situ hybridization}

Section $4 \mu \mathrm{m}$ of each case are used to perform HPV RNA ISH test. Detection of high-risk-HPV E6/E7 mRNA was performed using Ready-to-use reagents from RNAscope 2.5 LS Reagent Kit-BROWN and the HPV-HR18 probe cocktail (Advanced Cell Diagnostics) that were loaded onto the Leica Biosystems' BOND RX Research Advanced Staining System according to the user manual (Doc. No. 322,100-USM). The slides were independently evaluated by three separate observers. Ubiquitin $\mathrm{C}$ and dapB were used as positive and negative controls, respectively. A positive HPV ISH test result was defined as positive if any of the malignant cells showed brown punctate dot-like nuclear and/or cytoplasmatic positivity [27].

\section{Multiplex HPV RNA in situ hybridization/p16 immunohistochemistry}

We performed the multiplex HPV RNA ISH /p16 IHC assay according to the protocol previous reported [25].

The protocol utilizes the Diaminobenzidine (DAB) chromogen of the Bond Polymer Refine kit to staining HPV E6/E7 mRNA, the Fast Red chromogen of the Bond Polymer Red Refine kit to staining p16 and hematoxylin to counterstain. Detection of high-risk-HPV E6/E7 mRNA was performed using ready-to-use reagents from RNAscope ${ }^{\oplus} 2.5$ LS Reagent Kit-BROWN and the HPV-HR18 probe cocktail (Advanced Cell Diagnostics) that were loaded onto the Leica Biosystems' BOND RX Research Advanced Staining System according to the user manual (Doc. No. 322,100-USM). The target-specific probes include the E6 and E7 mRNA of 18 h-HPV genotypes HPV (16,18, 26,31, 33, 35, 39, 45, $51,52,53,56,58,59,66,68,73$ and 82). The Ubiquitin $\mathrm{C}$ a constitutively expressed endogenous gene was used as positive control to assess the presence adequate RNA quality and avoid a false-negative result. The dapB test was used as negative control to assess non-specific staining, for a comparison in the cases with negative or weakly stained HPV staining.

In brief, $4 \mu \mathrm{m}$ sections were baked and deparaffinized on the instrument, followed by epitope retrieval using Leica Epitope Retrieval Buffer 2 at $95{ }^{\circ} \mathrm{C}$ or at $88{ }^{\circ} \mathrm{C}$ for $15 \mathrm{~min}$ and protease treatment $15 \mathrm{~min}$ at $40{ }^{\circ} \mathrm{C}$. Probe hybridization, signal amplification trough different AMP reagent AMP 1-6) and colorimetric detection were subsequently performed. Several washes were performed, subsequently the ready-to-use primary antibody clone E6H4 for the detection of p16INK4a antigen was incubated and colorimetric detection was performed. Finally, a hematoxylin staining was carried out.

When the run is completed and the slide trays are removed, the covertiles are carefully lifted upward by the neck to remove. The slides are dehydrated through 2 changes each of $70 \%, 95 \%$, and $100 \%$ alcohol and 2 changes of xylene, before coverslipping. A positive HPV ISH test result was defined as positive if any of the malignant cells showed brown punctate dot-like nuclear and/or cytoplasmatic positivity. p16 IHC was positive if nuclear and cytoplasmic red staining was observed according to the above score. The slides were independently analyzed by three separate observers evaluating simultaneously HPV mRNA and p16 expression.

\section{Results}

\section{Clinic-pathological features}

In our series, patients older than 60 years were 28; the tumor site was the glans in 54 cases, the foreskin in 3 and the shaft in 3 . Usual squamous cell carcinoma (USCC) was observed in 49, whilest a special histotype in 11 (papillary in 2 cases, verrucous in 3 cases, basaloid in 4 cases, warty in 1 case and mixed warty-basaloid in 1 case). In USCC histotype, the low grade (G1) was recorded in 15 cases, the moderate grade (G2) in 22, the high grade (G3) in 13. The grade was not applicable in 10 cases since they were special types and in situ carcinomas. Finally, the tumors were staged T1 in 19 cases, T2 in $17, \mathrm{~T} 3$ in 11 and $\mathrm{T} 4$ in 3 , two cases were in situ carcinoma and the stage was not available in 8 cases. The data were reported in Table 1.

\section{P16 immunohistochemisty and HPV ISH}

P16 overexpression was recorded in 28 cases, 19 in USCC; 9 in special histotypes, p16 overexpression was equally distributed in older and younger patients. Particularly, p16 low intensity expression was observed in 5 cases $(8.3 \%)$, moderate in 3 cases (5\%) and high intensity in 20 cases (33.3\%).

HPV-ISH was observed in 15 cases, 9 in USCC; 6 in special histotypes, HPV-ISH positivity was more frequent in older patients, being observed in 9 cases older than 60 yrs.

The data of multiplex approach were fully concordant with single approach methods, also considering the cutoff values and the intensity of p16 overexpression. Notably, all HPV-ISH positive cases overexpress p16 (Figs. 1 and 2); while p16 overexpression (5 cases with low intensity; 3 with moderate intensity and 5 with high intensity) was also observed in $13 \mathrm{HPV}$-ISH negative cases (Table 2) (Fig. 3).

Thus, when considering only the cut-off without the intensity, p16 IHC showed a sensitivity of $100 \%$ and a specificity of $71 \%$, with a positive predictive value (PPV) of $54 \%$ and a negative predictive value of $100 \%$; when considering cut-off combined to high intensity, p16 IHC showed a sensitivity of $100 \%$, a specificity of $89 \%$, with a PPV of $75 \%$ and NPV of $100 \%$ (Table 3). 
Table 1 Clinical and pathological features of penile carcinomas in our series

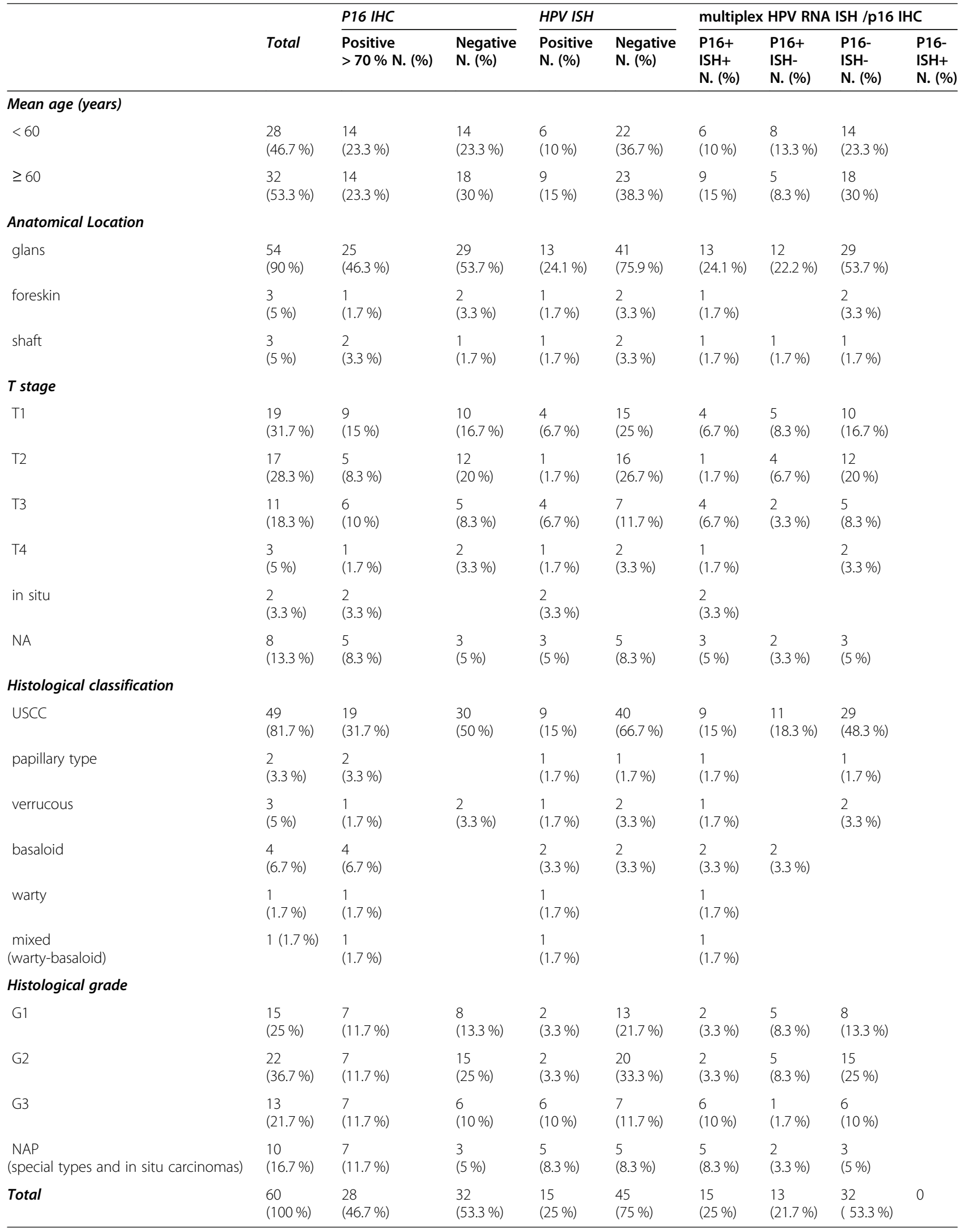

USCC usual squamous cell carcinoma; NA not available; NAP not applicable 

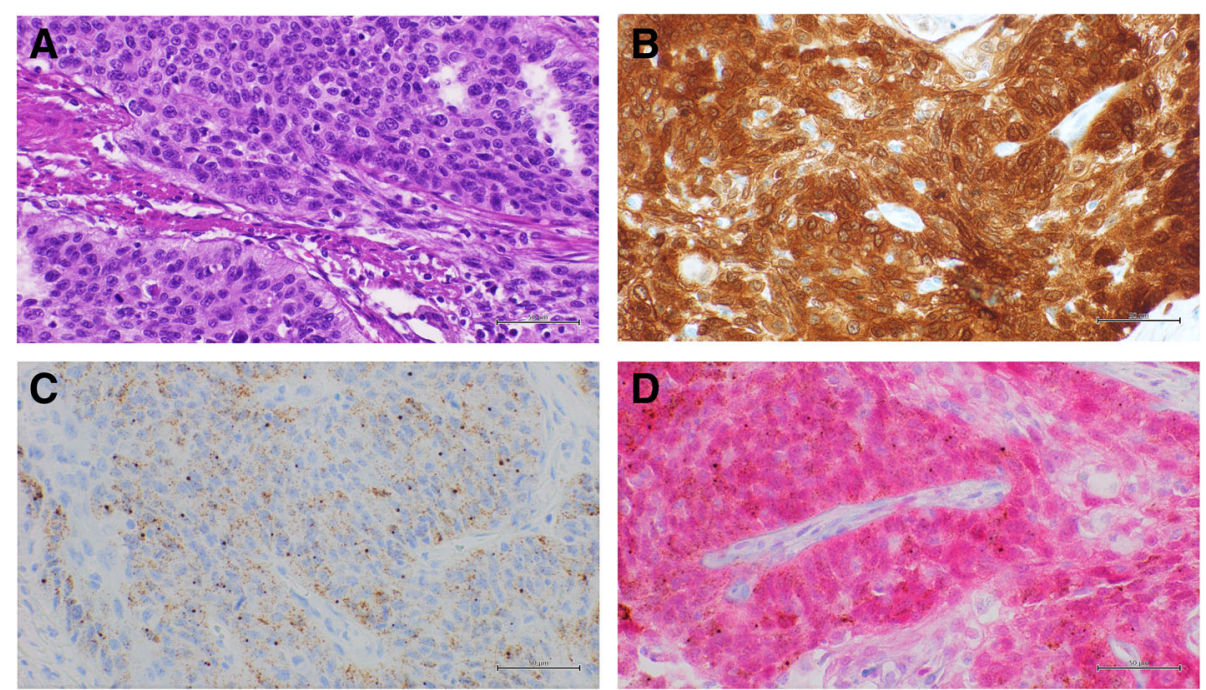

Fig. 1 Representative results of a basaloid penile carcinoma with high p16 IHC expression and HPV RNA expression. a: Hematoxylin and Eosin (H \& E) staining (40x); b: positive p16 IHC, DAB staining (40x); c: positive HPV RNA in situ hybridization, DAB staining (40x); d: multiplex HPV RNA ISH/ p16 IHC: positive p16 IHC Fast Red staining and positive HPV RNA ISH DAB staining (40x)

\section{Discussion}

The role of HPV is well documented in the pathogenesis of several human cancer types, including cervical, oropharyngeal, penile, vaginal, vulvar and anal cancers [28]. Indeed, HPV is associated with the development of approximately $90 \%$ of cervical carcinomas and the prophylactic vaccination is recommended in girls in order to prevent the infection [18]. In contrast, there is no recommendation for the use of the HPV prophylactic vaccination in boys due to the differences in the risk patterns for HPV-related PC [16, 17].

Although the frequency of the HPV in PC is lower than in cervical cancer, the HPV-related PCs constitute a subgroup with distinct biology and generally associated with a better prognosis and good response to the treatment than HPV-unrelated cancer. The new WHO classification has well identified a subset of PCs whose etiopathogenesis is closely associated with HPV infection. The accurate identification of the HPV-related PCs is necessary for the appropriate classification and management of these tumors.

Previous findings in PC demonstrated the overall correspondence of p16 IHC overexpression and the HPV presence; a strong association $(p<0.000001)$ was reported between HR-HPV and p16 showing entire and continuous cytoplasmic or nuclear staining in all neoplastic cells, except in the hyperkeratotic or parakeratotic areas when present [8]. Although the strong association with the molecular assay, p16 IHC shows a sensitivity of $67 \%$ (95\% CI: $57-75 \%$ ) and a specificity of $91 \%$ (95\% CI: $88-95 \%$ ) for the identification of HPV infection, suggesting a limited diagnostic capability of such test in detecting HPV [8].

Martins and colleagues showed that up to $50 \%$ of PC cases positive to HPV molecular assay were negative for p16 IHC expression; in addition, 21 out of 22 cases positive for p16 IHC were confirmed for the presence of HPV [29]. Similarly do Carmo Alves Martins et al. demontrated that the p16 overexpression was observed exclusively in 12 out of 26 HPV PCR-positive cases with 8 out of 12 HPV-16 positive cases. Furthermore, 4 HPV PCR-negative cases showed p16 overexpression [30].

The discordance between HPV PCR assay and p16 expression could be explained by biological reasons, including a non-oncogenic or transient HPV infection, an inactivation of $C D N K 2 A$, the gene encoding for p16, due to the loss of heterozygosity or the promoter hypermethylation $[8,24]$.

Beyond biological issues, the p16 IHC positivity in cases defined as HPV negative through PCR methods could be attributed to a detection failure associated with the technical limits, such as the DNA degradation [8].

Although the PCR assay currently represents the gold standard for the HPV detection and genotyping, this method is mainly indicated in fresh-frozen samples while it has a limited yield in FFPE $[25,31]$.

The RNA ISH is an innovative tool to detect the HPV E6/E7 mRNA transcripts on FFPE samples, providing information not only related to the presence of the virus but also the transcriptionally-active status [32]. The RNA ISH has significantly improved the detection of 

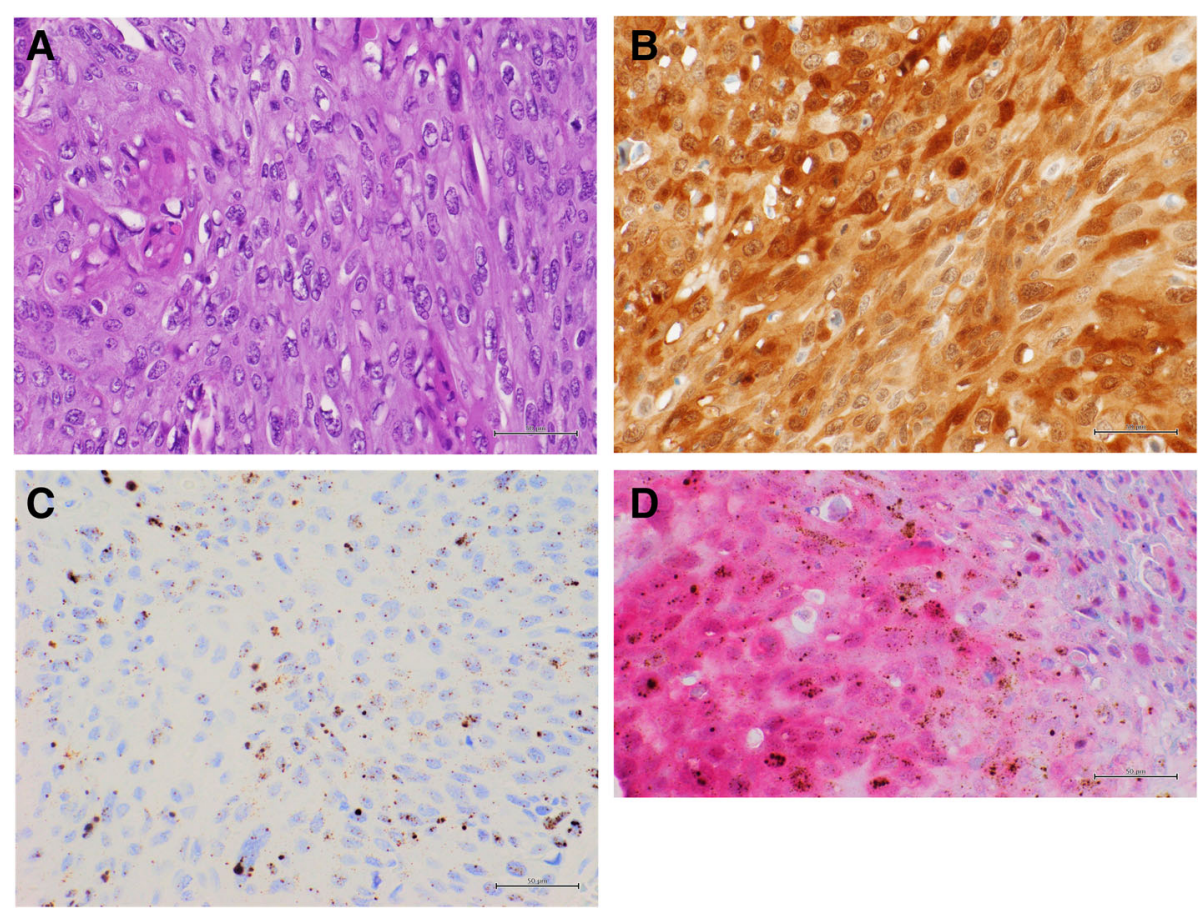

Fig. 2 Representative results of a warty penile carcinoma with high p16 IHC expression and HPV RNA expression. a: Hematoxylin and Eosin (H \& E) staining (40x); b: positive p16 IHC, DAB staining (40x); c: positive HPV RNA in situ hybridization, DAB staining (40x); d: multiplex HPV RNA ISH/ p16 IHC: positive p16 IHC Fast Red staining and positive HPV RNA ISH DAB staining (40x)

HR-HPV in OPSCC, leading to an accurate diagnosis of misclassified cases through p16 IHC [26].

In OPSCC, the combination of various assays to detect HPV improves the accuracy compared to the use of a single method, thus diagnostic algorithm including p16 IHC and molecular approaches is used in the clinical practice [25]. The discordance between p16 expression and ISH techniques used for HPV detection has been previously reported, particularly, using HPV ISH as a gold standard in oropharyngeal SCC, p16 IHC expression for HPV detection has been reported to have a variable sensitivity and specificity, ranging from 53 to $100 \%$ and from 54 to $100 \%$ respectively [33]. Both sensitivity

Table 2 Correspondence between p16 immunohistochemical expression and the HPV RNA ISH in our series

\begin{tabular}{lll}
\hline $\boldsymbol{P}$ 16 IHC & HPV ISH & \\
\cline { 2 - 3 } & $\boldsymbol{N}$. Pos (\%) & $\boldsymbol{N} . \mathbf{N e g}(\%)$ \\
\hline negative & $0(0 \%)$ & $32(53,3 \%)$ \\
low & $0(0 \%)$ & $5(8.3 \%)$ \\
moderate & $0(0 \%)$ & $3(5 \%)$ \\
high & $15(25 \%)$ & $5(8.3 \%)$ \\
Total & $15(25 \%)$ & $45(75 \%)$ \\
\hline
\end{tabular}

and specificity are better when considering RNA ISH as the gold standard rather than DNA ISH [33]. Thus, p16 might be an optimal surrogate, but it is expressed in other HPV-unrelated tumors. Further ambiguity of p16 overexpression is related to the used cut-off $>70 \%$ and the intensity of the tumor cells [33]. Not extensive experiences of HPV detection in PCs are reported. Particularly, extraction methods for HPV DNA detection revealed a concordance of HPV positive sample with p16 overexpression from 83.1 to $85.3 \%$ of cases $[6,15]$. Rare series reported the comparison of HPV-ISH and p16 overexpression, underlying HPV RNA-ISH and p16 overexpression discordance, with both more 16 overexpressing tumors respect to HPV-ISH positivity cases and vice versa $[34,35]$.

Our data showed 13 discordant cases between HPV RNA ISH and p16 IHC results, considering only the cut-off without the intensity of p16 expression. However, when considering the cut-off combined to the expression intensity, there were, the 5 discordant cases. Particularly, when considering only the cut off of $70 \%$ without the intensity of p16 expression, the concordance was recorded in $78.3 \%$ of cases, p16 being more frequently positive, with a sensitivity of $100 \%$, a specificity of $71 \%$, a PPV of 

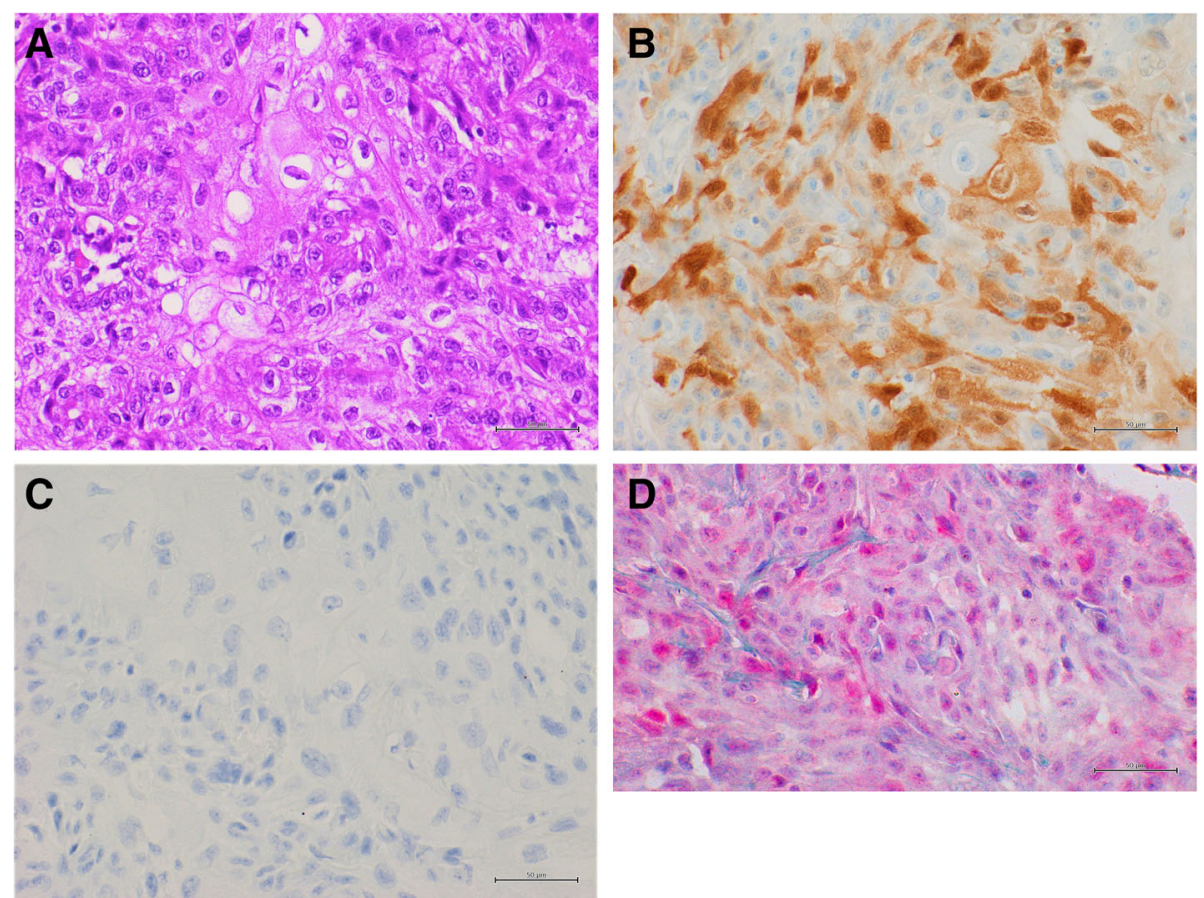

Fig. 3 Representative results of a usual squamous cell penile carcinoma with high p16 and HPV RNA ISH negative. a: Hematoxylin and Eosin (H \& E) staining (40x); b: positive p16 IHC, DAB staining (40x); c: negative HPV RNA in situ hybridization, DAB staining (40x); d: multiplex HPV RNA ISH/ p16 IHC: positive p16 IHC Fast Red staining and negative HPV RNA ISH DAB staining (40x)

$54 \%$ and a NPV of $100 \%$. Furthermore, considering a combined score including the cut off of $70 \%$ and the high intensity of p16 IHC expression, the concordance was recorded in $91.7 \%$ of cases, with a sensitivity of $100 \%$, a specificity of $89 \%$, a PPV of $75 \%$ and a NPV of $100 \%$. Thus, p16 overexpression could be un-related to HPV oncogenic role in PC in at least $8,3 \%$ of cases, also considering that such cases did not show HPV related morphology.

In this perspective, as in other district, the multimodal approach based on p16 IHC and HPV detection by molecular assay in PCs leads to a better identification of HPV-related subgroup, reducing the rate of both falsenegative and false-positive cases $[8,12,24,30]$. In consideration of the prognostic and predictive value of HPV infection, the choice of an accurate diagnostic assay for

Table 3 Specificity and Sensitivity of p16 IHC in our series

\begin{tabular}{lll}
\hline & P16 IHC low/moderate/high & P16 IHC high \\
\hline specificity & $71 \%$ & $89 \%$ \\
sensitivity & $100 \%$ & $100 \%$ \\
PPV & $54 \%$ & $75 \%$ \\
NPV & $100 \%$ & $100 \%$ \\
\hline
\end{tabular}

IHC immunohistochemistry; PPV positive predictive value; NPV negative predictive value
HPV detection is critical to define the most optimal management and follow-up for PC patients.

\section{Conclusions}

Multiplex assay in the clinical practice could help to define the HPV-related PC subgroup avoiding the misclassification of these tumors. Our data confirm a high NPV of p16 intense overexpression, but a lower PPV, 8, $3 \%$ being the cases overexpressing p16 in absence of HPV-RNA. Thus, as p16 is a parameter potentially, but not exclusively, associated to HPV oncogenic activity, the multiplex approach let a simultaneous study of the HPV presence and its activity, differentiating the HPVrelated from HPV-unrelated PCs. In conclusion, the multiplex HPV RNA ISH /p16 IHC assay could solve the diagnosis of HPV, especially in cases with discordant results. This approach has several advantages including the identification of the transcriptionally-active HPV and p16 on the same slide using a single technical approach, high performance in FFPE specimens, the complete not operator-dependent automation and the interpretation in the light field. Overall, the advantages of this new tool may allow wide spreadable for HPV routine testing in PC. Finally, our multiplex assay could help in the clinical practice the definition of HPV-related PC subset avoiding the misclassification of these tumors. 


\section{Abbreviations}

PC: Penile carcinoma; HPV: Human papillomavirus; HR-HPV: High-risk HPV; WHO: World Health Organization; PCR: Polymerase chain reaction; IHC: Immunohistochemistry; ISH: In situ hybridization; OPSCC: Oropharyngeal squamous cell carcinoma; Multiplex HPV RNA ISH /p16 IHC: Multiplex HPV RNA in situ hybridization/p16 Immunohistochemistry; FFPE: Formalin-fixed paraffin-embedded; DAB: Diaminobenzidine; USCC: Usual squamous cell carcinoma; PPV: Positive predictive value; NPV: Negative predictive value

\section{Authors' contributions}

FZM and RF: conceived the study, methodology, investigation, original draft writing; GA, MB, LN, GB, FF, GT, FP: provided tissue samples, revised the tumor areas and the histotypes according to the histological classification; FZM and RS: performed RNA ISH, IHC, and multiplex ISH/IHC assays; SP, GF, GDL, RBDR: provided clinical and pathological features of the patients; RF, FZM, MB: interpreted RNA ISH, IHC, and multiplex ISH/IHC. The author(s) read and approved the final manuscript.

\section{Declarations}

\section{Competing interests}

The authors declare that they have no conflict of interest

\section{Author details}

${ }^{1}$ Pathology Unit, Department of Mental and Physical Health and Preventive Medicine, University of Campania "L. Vanvitelli", Complesso di Santa Patrizia Via Luciano Armanni, 5, 80138 Naples, Italy. 'Department of Pathology, University of Verona, Verona, Italy. ${ }^{3}$ Pathology Unit, Istituto Nazionale Tumori, Fondazione G. Pascale, IRCCS, 80131 Naples, Italy. ${ }^{4}$ Department of Urology, Istituto Nazionale Tumori, Fondazione G. Pascale, IRCCS, 80131 Naples, Italy. ${ }^{5}$ Medical Oncology Unit, S.M. delle Grazie Hospital, Via Domitiana, 80078 Pozzuoli, NA, Italy. 'Pathology Unit, S.M. delle Grazie Hospital, Via Domitiana, 80078 Pozzuoli, NA, Italy. ${ }^{7}$ Urology Unit, S.M. delle Grazie Hospital, Via Domitiana, 80078 Pozzuoli (NA), Italy. ${ }^{8}$ Urology Unit, Department of Woman, Child and General and Specialized Surgery, University of Campania 'Luigi Vanvitelli, 80138 Naples, Italy. ${ }^{9}$ Division of Medical Oncology, Department of Precision Medicine, School of Medicine, "Luigi Vanvitelli" University of Campania, Naples, Italy. ${ }^{10}$ Laboratoire Central d'Anatomie pathologique, Hôpital universitaire de Nice, Université Côte d'Azur, 06000 Nice, France. ${ }^{11}$ Department of Surgery and Anatomy, Urology Division, Ribeirao Preto School Medicine, University of São Paulo, 14049900 Ribeirao Preto, Brazil. ${ }^{12}$ Department of Pathology and Forensic Medicine, Ribeirão Preto Medical School, University of São Paulo, 14049900 Ribeirão Preto, SP, Brazil.

${ }^{13}$ Molecular Oncology Research Center, Barretos Cancer Hospital, 14784400 Barretos, SP, Brazil.

\section{Received: 31 January 2021 Accepted: 19 March 2021} Published online: 31 March 2021

\section{References}

1. Bleeker MC, Heideman DA, Snijders PJ, Horenblas S, Dillner J, Meijer C. Penile cancer: epidemiology,pathogenesis and prevention. World J Urol. 2009;27(2):141 \pm 50. https://doi.org/10.1007/s00345-008-0302-z.

2. Morrison BF. Risk factors and prevalence of penile cancer. West Indian Med J. 2014 Oct;63(6):559 \pm 560. https://doi.org/10.7727/wimj.2015.381.

3. Spiess PE, Dhillon J, Baumgarten AS, Johnstone PA, Giuliano AR. Pathophysiological basis of human papillomavirus in penile cancer: Key to prevention and delivery of more effective therapies. CA Cancer J Clin. 2016 Jun 17; 66:481 \pm 95. https://doi.org/10.3322/caac.21354.

4. Hakenberg $\mathrm{OW}$, Dräger $\mathrm{DL}$, Erbersdobler $\mathrm{A}$, Naumann $\mathrm{CM}$, Jünemann KP, Protzel C. The Diagnosis and Treatment of Penile Cancer. Dtsch Arztebl Int 2018 Sep 28;115(39):646-652. doi: https://doi.org/10.3238/arztebl.2018.0646.

5. Afonso LA, Cordeiro TI, Carestiato FN, Ornellas AA, Alves G, Cavalcanti SM. High risk human papillomavirus infection of the foreskin in asymptomatic men and patients with phimosis. J Urol. 2016 Jun;195(6):1784 \pm 9. https:// doi.org/10.1016/j.juro.2015.12.096.

6. Alemany L, Cubilla A, Halec G, Kasamatsu E, Quirós B, Masferrer E, Tous S, Lloveras B, Hernández-Suarez G, Lonsdale R, Tinoco L, Alejo M, AlvaradoCabrero I, Laco J, Guimerà N, Poblet E, Lombardi LE, Bergeron C, Clavero O, Shin HR, Ferrera A, Felix A, Germar J, Mandys V, Clavel C, Tzardi M, Pons LE, Wain V, Cruz E, Molina C, Mota JD, Jach R, Velasco J, Carrilho C, López-
Revilla R, Goodman MT, Quint WG, Castellsagué X, Bravo I, Pawlita M, Muñoz N, Bosch FX, de Sanjosé S. HPV WAP study group. Role of Human Papillomavirus in Penile Carcinomas Worldwide. Eur Urol. 2016 May;69(5): 953-61. doi:https://doi.org/10.1016/j.eururo.2015.12.007.

7. Cubilla AL, Lloveras B, Alejo M, Clavero O, Chaux A, Kasamatsu E, et al. The basaloid cell is the best tissue marker for human papillomavirus in invasive penile squamous cell carcinoma: a study of 202 cases from Paraguay. Am J Surg Pathol. 2010;34(1):104-14. https://doi.org/10.1097/PAS.

8. Cubilla AL, Lloveras B, Alejo M, Clavero O, Chaux A, Kasamatsu E, et al. Value of p16INK4a in the pathology of invasive penile squamous cell carcinomas: a report of 202 cases. Am j Surg Pathol. 2011;35(2):253-61. https://doi.org/1 0.1097/PAS.0b013e318203cdba.

9. Ferra'ndiz-Pulido C, Masferrer E, de Torres I, Lloveras B, Hernandez-Losa J, Mojal $S$, et al. Identification and genotyping of human papillomavirus in a Spanish cohort of penile squamous cell carcinomas: Correlation with pathologic subtypes, p16 INK4a expression, and prognosis. J Am Acad Dermatol. 2013;68(1):73-82. https://doi.org/10.1016/j.jaad.2012.05.029.

10. Steinestel J, Al Ghazal A, Arndt A, Schnoeller TJ, Schrader AJ, Moeller P, Steinestel K. The role of histologic subtype, p16(INK4a) expression, and presence of human papillomavirus DNA in penile squamous cell carcinoma. BMC Cancer. 2015 Apr 3;15:220. doi: https://doi.org/10.1186/ s12885-015-1268-z.

11. Lont AP, Kroon BK, Horenblas S, Gallee MP, Berkhof J, Meijer CJ, Snijders PJ. Presence of high-risk human papillomavirus DNA in penile carcinoma predicts favorable outcome in survival. Int J Cancer. 2006 Sep 1;119(5):107881. doi: https://doi.org/10.1002/ijc.21961. PMID: 16570278.

12. Sand FL, Rasmussen CL, Frederiksen MH, Andersen KK, Kjaer SK. Prognostic Significance of HPV and p16 Status in Men Diagnosed with Penile Cancer: A Systematic Review and Meta-analysis. Cancer Epidemiol Biomarkers Prev. 2018 Oct;27(10):1123-32. doi:https://doi.org/10.1158/1055-9965.EPI-18-0322.

13. Moch H, Cubilla AL, Humphrey PA, Reuter VE, Ulbright TM. The 2016 WHO Classification of Tumours of the Urinary System and Male Genital OrgansPart A: Renal, Penile, and Testicular Tumours. Eur Urol. 2016 Jul;70(1):93-105. doi:https://doi.org/10.1016/j.eururo.2016.02.029.

14. Brierley JD, Gospodarowicz MK, Wittekind C. (Editors). TNM classification of malignant tumours. Union for International Cancer Control; Oxford: John Wiley \& Sons; 2017.

15. Gu W, Zhang P, Zhang G, Zhou J, Ding X, Wang Q, Wang B, Wei Y, Jin S, Ye D, Zhu Y. Importance of HPV in Chinese Penile Cancer: A Contemporary Multicenter Study. Front Oncol. 2020 Sep 4;10:1521. doi: https://doi.org/1 0.3389/fonc.2020.01521.

16. Backes DM, Kurman RJ, Pimenta JM, Smith JS. Systematic review of human papillomavirus prevalence in invasive penile cancer. Cancer Causes Control. 2009 May;20(4):449-57. doi:https://doi.org/10.1007/s10552-008-9276-9.

17. Olesen TB, Sand FL, Rasmussen CL, Albieri V, Toft BG, Norrild B, Munk C, Kjær SK. Prevalence of human papillomavirus DNA and p16 ${ }^{I N K 4 a}$ in penile cancer and penile intraepithelial neoplasia: a systematic review and metaanalysis. Lancet Oncol. 2019 Jan;20(1):145-58. doi:https://doi.org/10.1016/ S1470-2045(18)30682-X

18. Takamoto D, Kawahara T, Kasuga J, Sasaki T, Yao M, Yumura Y, Uemura H. The analysis of human papillomavirus DNA in penile cancer tissue by in situ hybridization. Oncol Lett. 2018 May;15(5):8102-8106. doi: https://doi.org/10.3 892/ol.2018.8351.

19. Chaux A, Cubilla AL, Haffner MC, Lecksell KL, Sharma R, Burnett AL, Netto GJ. Combining routine morphology, p16(INK4a) immunohistochemistry, and in situ hybridization for the detection of human papillomavirus infection in penile carcinomas: a tissue microarray study using classifier performance analyses. Urol Oncol. 2014 Feb;32(2):171-7. doi:https://doi.org/10.1016/j. urolonc.2012.04.017.

20. Sakamoto J, Shigehara K, Nakashima K, Kawaguchi S, Nakashima T, Shimamura M, Yasuda M, Kato T, Hasegawa T, Kobori Y, Okada H, Deguchi T, Izumi K, Kadono Y, Mizokami A. Etiological role of human papillomavirus infection in the development of penile cancer. Int J Infect Dis. 2019 Jan; 78:148-154. doi: https://doi.org/10.1016/j.ijid.2018.11.003.

21. Klaes R, Friedrich T, Spitkovsky D, Ridder R, Rudy W, Petry U, DallenbachHellweg G, Schmidt D, von Knebel Doeberitz M. Overexpression of p16(INK4A) as a specific marker for dysplastic and neoplastic epithelial cells of the cervix uteri. Int J Cancer. 2001 Apr 15;92(2):276 - 84. doi: https://doi. org/10.1002/ijc.1174. PMID: 11291057.

22. Ferreux E, Lont AP, Horenblas S, Gallee MP, Raaphorst FM, von Knebel Doeberitz M, Meijer CJ, Snijders PJ. Evidence for at least three 
alternative mechanisms targeting the $\mathrm{p} 16 \mathrm{INK} 4 \mathrm{~A} / \mathrm{cyclin} \mathrm{D} / \mathrm{Rb}$ pathway in penile carcinoma, one of which is mediated by high-risk human papillomavirus. J Pathol. 2003 Sep;201(1):109-18. doi:https://doi.org/10.1 002/path.1394.

23. Fernández-Nestosa MJ, Guimerà N, Sanchez DF, Cañete-Portillo S, Velazquez EF, Jenkins D, Quint W, Cubilla AL. Human Papillomavirus (HPV) Genotypes in Condylomas, Intraepithelial Neoplasia, and Invasive Carcinoma of the Penis Using Laser Capture Microdissection (LCM)-PCR: A Study of 191 Lesions in 43 Patients. Am J Surg Pathol. 2017 Jun;41(6):820-32. doi:https:// doi.org/10.1097/PAS.0000000000000821.

24. Martínez-Bailón C, Mantilla-Morales A, Méndez-Matías G, Alvarado-Cabrero I, Maldonado-Rodríguez R, Quintero-Becerra J, Arias-Flores R, Piña-Sánchez P. Human papillomavirus genotypes and P16INK4A expression in squamous penile carcinoma in Mexican patients. BMC Infect Dis. 2019 Dec 19;19(1): 1068. doi: https://doi.org/10.1186/s12879-019-4696-6.

25. Zito Marino F, Ronchi A, Stilo M, Cozzolino I, La Mantia E, Colacurci N, Colella G, Franco R. Multiplex HPV RNA in situ hybridization/p16 immunohistochemistry: a novel approach to detect papillomavirus in HPV-related cancers. A novel multiplex ISH/IHC assay to detect HPV. Infect Agent Cancer. 2020 Jul 14;15:46. doi: https://doi.org/10.1186/s13 027-020-00310-x.

26. Bishop JA, Ma XJ, Wang H, Luo Y, Illei PB, Begum S, Taube JM, Koch WM, Westra WH. Detection of transcriptionally active high-risk HPV in patients with head and neck squamous cell carcinoma as visualized by a novel E6/E7 mRNA in situ hybridization method. Am J Surg Pathol. 2012 Dec;36(12):1874-82. doi:https://doi.org/10.1097/PAS.0b013 e318265fb2b.

27. Cohen C, Lawson D, Jiang J, Siddiqui MT. Automated in situ hybridization for human papilloma virus. Appl Immunohistochem Mol Morphol. 2014 Sep; 22(8):619-22. doi:https://doi.org/10.1097/PAl.0b013e3182a501a2.

28. Bansal A, Singh MP, Rai B. Human papillomavirus-associated cancers: A growing global problem. Int J Appl Basic Med Res. 2016 Apr-Jun;6(2):84-9. doi: https://doi.org/10.4103/2229-516X.179027.

29. Martins VA, Pinho JD, Teixeira Júnior AAL, Nogueira LR, Silva FF, Maulen VE, Khayat AS, Calixto JRR, Costa HA, Ramalho LNZ, Silva GEB. P16INK4a expression in patients with penile cancer. PLoS One. 2018 Oct 12;13(10): e0205350. doi: https://doi.org/10.1371/journal.pone.0205350.

30. Martins VDCA, Cunha IW, Figliuolo G, Rondon HHMF, de Souza PM, Torres Silva FL, Torres Silva GL, de Souza Bastos M, de Castro DB, Santana MF, Ramasawmy R, Levi JE, Torres KL. Presence of HPV with overexpression of p16INK4a protein and EBV infection in penile cancer-A series of cases from Brazil Amazon. PLoS One. 2020 May 6;15(5):e0232474. doi: https:/doi.org/1 0.1371/journal.pone.0232474.

31. Lenhoff A. Five. FDA-approved HPV assays. MLO Med Lab Obs. 2012 Jul; $44(7): 14,16,18$.

32. Lewis JS Jr, Ukpo OC, Ma XJ, Flanagan JJ, Luo Y, Thorstad WL, Chernock RD. Transcriptionally-active high-risk human papillomavirus is rare in oral cavity and laryngeal/hypopharyngeal squamous cell carcinomas-a tissue microarray study utilizing E6/E7 mRNA in situ hybridization. Histopathology. 2012 May;60(6):982-91. doi:https://doi. org/10.1111/j.1365-2559.2011.04169.x.

33. Suresh K, Shah PV, Coates S, Alexiev BA, Samant S. In situ hybridization for high risk HPV E6/E7 mRNA in oropharyngeal squamous cell carcinoma. Am J Otolaryngol. 2021 Jan-Feb;42(1):102782. doi: https://doi.org/10.1016/j.a mjoto.2020.102782.

34. Eich ML, Del Carmen Rodriguez Pena M, Schwartz L, Granada CP, RaisBahrami S, Giannico G, Amador BM, Matoso A, Gordetsky JB. Morphology. p16, HPV, and outcomes in squamous cell carcinoma of the penis: a multiinstitutional study. Hum Pathol. 2020 Feb;96:79-86. doi:https://doi.org/10.1 016/j.humpath.2019.09.013.

35. Zargar-Shoshtari K, Spiess PE, Berglund AE, Sharma P, Powsang JM, Giuliano A, Magliocco AM, Dhillon J. Clinical Significance of p53 and p16(ink4a) Status in a Contemporary North American Penile Carcinoma Cohort. Clin Genitourin Cancer. 2016 Aug;14(4):346-51. doi: https://doi.org/10.1016/j. clgc.2015.12.019

\section{Publisher's Note}

Springer Nature remains neutral with regard to jurisdictional claims in published maps and institutional affiliations.

Ready to submit your research? Choose BMC and benefit from:

- fast, convenient online submission

- thorough peer review by experienced researchers in your field

- rapid publication on acceptance

- support for research data, including large and complex data types

- gold Open Access which fosters wider collaboration and increased citations

- maximum visibility for your research: over $100 \mathrm{M}$ website views per year

At BMC, research is always in progress.

Learn more biomedcentral.com/submissions 